\title{
Improved Viability of Areca (Areca catechu L.) Seedlings under Drought Stress Using a Superabsorbent Polymer
}

\author{
Jia Li, Liyun Liu, and Huanqi Zhou \\ Coconut Research Institute, Chinese Academy of Tropical Agricultural \\ Sciences, Wenchang, Hainan, 571339, China
}

\author{
Meng $\mathbf{L i}^{1}$ \\ College of Life Science and Technology, Central South University of Forestry \\ and Technology, Changsha, Hunan, 410004, China
}

Additional index words. SAP, drought stress, seedling growth, chlorophyll fluorescence

\begin{abstract}
Areca (Areca catechu L.) is a tropical plant with great economic importance. In China, the fruit of areca (betel nut) is produced mainly in Hainan Province. However, the yield of betel nuts was impacted seriously by frequent water deficits in Hainan Province. Drought causes deleterious effects on the growth and development of areca plants, especially on young seedlings, which hampered the extensive planting of areca. In this study, a reagent of a superabsorbent polymer (SAP) was applied into the culture soil and we analyzed its function against drought stress when seedlings were grown under different irrigation levels. We observed that SAP application caused a significant increase in plant weight under severe drought, as well as in the maximum photochemical efficiency of PSII $\left(F_{v} / F_{m}\right)$ and actual photochemical efficiency of PSII [Y(II)] index of chlorophyll (chl), indicating the photosynthetic efficiency of seedlings under severe drought (D) was enhanced by SAP. The antioxidant enzyme activity of areca seedlings under $D$ was indicated to be enhanced by the increasing activity of superoxide dismutase (SOD) and peroxidase (POD), but not catalase (CAT). In addition, SAP even has slight negative effects on the growth of seedlings under adequate water. Our results provide a theoretical basis to improve the viability of areca seedlings under severe drought using SAP, which is urgently needed for the market.
\end{abstract}

Areca palm (Areca catechu L.) is widely distributed in South and Southeast Asia. Its fruit, the betel nut, is a traditional herbal medicine, which is popular in Southeast Asia. Betel nuts are often chewed by tropical residents for the purpose of relieving accumulated fluid in the abdominal cavity (Peng et al., 2015). The areca palm tree is adapted to tropical places with hot and wet climates, in which the annual precipitation ranges from 1500 to $2200 \mathrm{~mm}$. More than 150,000 ha of areca were planted; it is the most important cash crop in Hainan Province, China. However, most of these planting areas are mountainous and precipitation is quite uneven, resulting in the areas that suffer from drought. A water deficit usually occurs from November to April, which is a critical period for the survival and growth of areca

Received for publication 18 Sept. 2018. Accepted for publication 10 Oct. 2018 .

This work was supported by grants from the Central Public-interest Scientific Institution Basal Research Fund for Innovative Research Team Program of CATAS (no. 1630152017014), Hainan Major Research Program of Science and Technology (ZDKJ201817), and The Key Research and Development Program of Hainan Province (ZDYF2017069).

${ }^{1}$ Corresponding author. E-mail: limeng0422@foxmail. com. seedlings. Therefore, it is necessary to develop strategies to improve irrigation efficiency and to optimize the use of scattered rainfall in areca cultivation areas, most of which are arid and semiarid.

Drought stress is one of the most important environmental factors limiting plant growth, productivity, and survival (Ndamani and Watanabe, 2015). Common plant symptoms of water deficit include stunted growth, limited carbon dioxide diffusion to chloroplasts by stomatal closure, reduced photosynthesis rate, and accelerated leaf senescence (Flexas et al., 2010). Water deficit stress reduces plant yield and production, and is the main limiting factor for oil palm and date palm productivity (Rivera Méndez et al., 2012; Yaish and Kumar, 2015). Drought stress will induce overproduction of reactive oxygen species (ROS), including the superoxide radical $\left(\mathrm{O}_{2}^{-}\right)$and hydrogen peroxide $\left(\mathrm{H}_{2} \mathrm{O}_{2}\right)$, which have detrimental effects on plants through damaging the membranes, proteins, $\mathrm{chl}$, and nucleic acids of plant cells (Apel and Hirt, 2004). To eliminate or minimize oxidative damage, plants have evolved an antioxidant defense system consisting of both nonenzymatic and enzymatic mechanisms in plant cells (Sairam et al., 2011). A number of oxidoreductases, such as SOD, POD, and $\mathrm{CAT}$, are involved in this process. The balance between ROS production and antioxidant enzyme activity determines whether oxidative signaling and damage occur (Gill and Tuteja, 2010). The increased production of superoxide radicals and $\mathrm{H}_{2} \mathrm{O}_{2}$ is always paralleled by malondialdehyde (MDA) accumulation under drought stress (Porcel and Ruiz-Lozano, 2004). MDA is a decomposition product of polyunsaturated fatty acids existing in cell membranes and is an important indicator of membrane damage (Jiang and Zhang, 2001).

According to previous reports, photosynthetic performance is identified as a very informative indicator of drought stress with exceptional sensitivity (Massacci et al., 2008; Woo et al., 2008). Besides the classic measurements of photosynthesis by gas exchange analysis, chl fluorescence analysis has become a more widely used method to detect the function of the photosynthetic apparatus. In addition, it is a powerful tool for monitoring plants' response to drought stress (Guo et al., 2016; Sperdouli and Moustakas, 2011). Chl fluorescence imaging has been used to reveal spatial and temporal changes during the developmental stages of plants grown under stress in a large number of studies (Lu et al., 2015; Sperdouli and Moustakas, 2011; Wang et al., 2016; Yang et al., 2014).

The application of an SAP could be one way to cope with the detrimental effects caused by drought (Smagin et al., 2014). SAPs are hydrophilic networks that can absorb and retain huge amounts of water or aqueous solutions (Zohuriaan-Mehr and Kabiri, 2008). The SAP particles can be thought of as "miniature water reservoirs" in soil. When SAP hydrogels are incorporated into soil, they are presumed to retain large quantities of water and nutrients, which are released to satisfy the requirements of plants (Lentz and Sojka, 1994). Previous documents have confirmed that SAP application is effective at mitigating the effects caused by drought stress on diverse plants (Islam et al., 2011; Tongo et al., 2014). The application of SAPs to soil may reduce soil penetration resistance, increase soil waterholding capacity, and aid in the protection of soil organic matter (Busscher et al., 2009).

In this study, we examined the effects of SAP application on growth characteristics, biochemical exchanges, and the activity of different antioxidant enzymes in leaves of areca seedlings under drought stress. Our results indicated discrepant effects of SAP on areca seedlings under different irrigation levels.

\section{Materials and Methods}

Plants and water supply management. All plant materials were growing in a greenhouse at the Coconut Research Institute at the Chinese Academy of Tropical Agricultural Sciences (Wenchang, Hainan Province, China), from May 2016 to Mar. 2017. An areca cultivar, Reyan No. 1, was used in the current study. Before sowing, the seeds were surface sterilized with $0.5 \%$ potassium permanganate solution. Three seeds were sown per pot (diameter, $15 \mathrm{~cm}$; height, $20 \mathrm{~cm}$ ), and 30 pots were sown in total on 13 May 2016. Mixture medium consisted of garden soil, coconut coir, 
and organic fertilizer 3:1:1 (v/v/v), and was used for plant growth. The soil water field capacity was $38.25 \%$, the content of organic matter was $0.27 \mathrm{~g} \cdot \mathrm{kg}^{-1}$, and the available nitrogen, phosphorus, and potassium were $20.35,53.22$, and $90.92 \mathrm{mg} \cdot \mathrm{kg}^{-1}$, respectively. The pots were initially well watered to ensure seed germination. When the first true leaf was present, the seedlings were thinned to one plant per pot. Healthy seedlings with three leaves
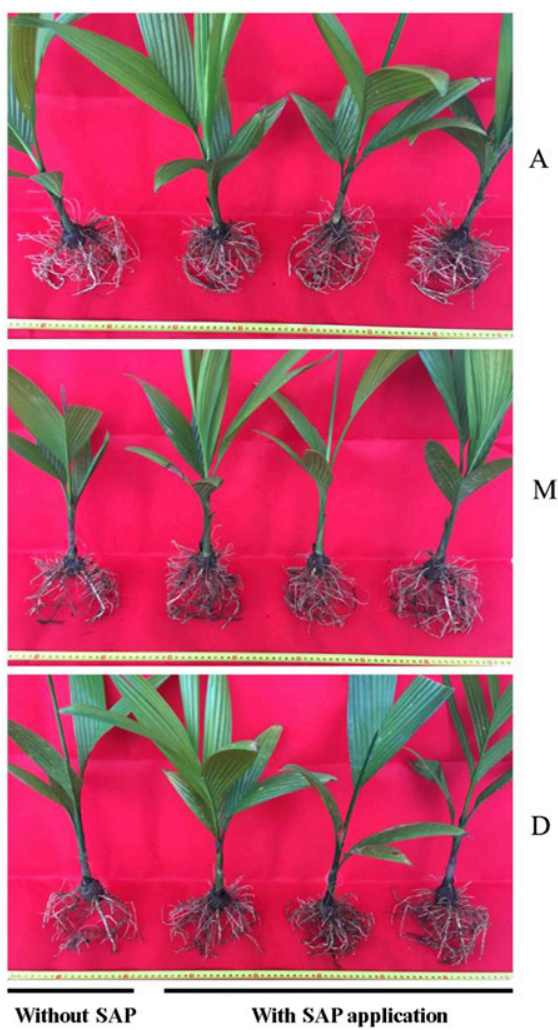

Fig. 1. Morphological features of A. catechu seedlings under different irrigation (A, adequate; $\mathrm{M}$, moderate; $\mathrm{D}$, deficit) and superabsorbent polymer (SAP) treatments.
Fresh weight

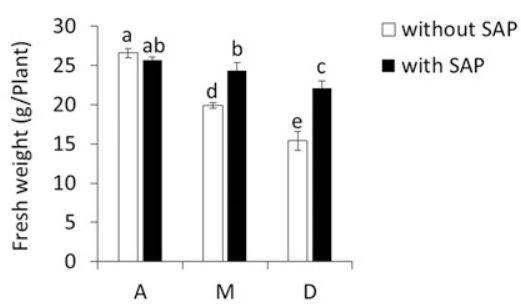

Subterranean parts

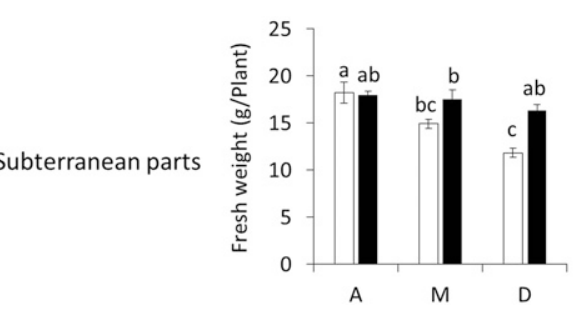

were used. The SAP (acrylamide-potassium acrylata copolymer, granular; Beijing Hanlimiao Ltd. Co., Beijing, China) was applied at a $15-\mathrm{cm}$ depth into the soil at $0.25 \%$ concentration $(\mathrm{w} / \mathrm{w})$, which was considered the standard rate of SAP application. Three irrigation treatments were applied: 1 ) adequate water (A, $75 \pm 5 \%$ field water capacity), 2) mild drought (M, $40 \pm 5 \%$ field water capacity), and 3) severe drought $(\mathrm{D}, 20 \pm 5 \%$ field water capacity). The water loss in the pot was measured by a weighing method. We weighed the pots every $2 \mathrm{~d}$, and the difference between two measurements was considered the value of water loss. Then, a corresponding amount of water was added into the pot to keep the water content unchanged.

Phenological measurements and calculations. Three irrigation regimes (A, M, and D) and two SAP application treatments (with SAP and without SAP) were combined into a total of six treatments. Five randomly chosen seedlings were used in each treatment as biological replicates. After 8 weeks of treatment, seedling chl fluorescence parameters, RWC (relative water content), chl content, MDA content, and antioxidant enzyme activities were measured. Chl fluorescence parameters were measured around midday (10:30 AM-12:30 PM) on random samples of fully expanded leaves. For biochemical analysis, the samples were frozen immediately in liquid nitrogen and stored at $-80^{\circ} \mathrm{C}$. Data on aerial and subterranean parts of seedling dry weight were obtained 9 weeks after treatment.

Growth measurements. After the treatment, the seedlings were harvested, washed carefully, and divided into aerial and subterranean parts. The samples were stirred at $105{ }^{\circ} \mathrm{C}$ then oven-dried for $72 \mathrm{~h}$ at $80^{\circ} \mathrm{C}$ to measure the dry weights (five plants per treatment).

Chlorophyll fluorescence measurements. $\mathrm{Chl}$ fluorescence was measured using a portable PAM-2500 fluorometer (Walz, Ger-

Fig. 2. Fresh weight and dry weight of $A$. catechu seedlings under various irrigation (A, adequate; M, moderate; D, deficit) and superabsorbent polymer (SAP) treatments. The small bars show SD. Different letters represent significant differences at $P<0.05$ according to Duncan's multiple range tests. many) equipped with computer-operated PAM-control software (PAMWin 3.0). The photochemical quenching $(\mathrm{qP})=\left(\mathrm{F}_{\mathrm{m}}-\mathrm{F}_{\mathrm{s}}\right) /$ $\left(\mathrm{F}_{\mathrm{m}}{ }^{\prime}-\mathrm{F}_{\mathrm{o}}{ }^{\prime}\right)$, nonphotochemical quenching $(\mathrm{NPQ})=\left(\mathrm{F}_{\mathrm{m}}-\mathrm{F}_{\mathrm{m}}{ }^{\prime}\right) / \mathrm{F}_{\mathrm{m}}{ }^{\prime}$, maximum photochemical efficiency of PSII $\left(\mathrm{F}_{\mathrm{v}} / \mathrm{F}_{\mathrm{m}}, \mathrm{F}_{\mathrm{v}}=\mathrm{F}_{\mathrm{m}}\right.$ $F_{o}$ ), and actual photochemical efficiency of PSII Y (II) $=\left(\mathrm{F}_{\mathrm{m}}{ }^{\prime}-\mathrm{F}_{\mathrm{s}}\right) / \mathrm{F}_{\mathrm{m}}{ }^{\prime}$ were calculated according to the methods of Schreiber et al. (1986).

$R W C$ measurement. RWC of leaves was measured according to the methods of Barrs and Weatherley (1962). After sampling, leaves were weighed immediately and then soaked in distilled water at room temperature overnight. They were then blotted dry and weighed before oven-drying at $80^{\circ} \mathrm{C}$ for $48 \mathrm{~h}$. RWC was calculated using the following formula: $\mathrm{RWC}=[(\mathrm{FW}-\mathrm{DW}) /(\mathrm{TW}-\mathrm{DW})] \times$ $100 \%$, where FW is fresh weight, DW is dry weight, and TW is turgid weight (weight after the leaf was kept in distilled water overnight).

MDA measurement. Lipid peroxidation was estimated from the level of MDA production using thiobarbituric acid (TBA) according to the methods of Sairam and Srivastava (2010). Fresh leaf (1 g) was homogenized in $10 \mathrm{~mL} 0.1 \%$ trichloroacetic acid (TCA) and centrifuged at 10,000 rpm for $10 \mathrm{~min}$. The mixture containing $1 \mathrm{~mL}$ sample supernatant, $4 \mathrm{~mL} \mathrm{20 \%} \mathrm{TCA}$, and $0.5 \%$ TBA was heated at $95{ }^{\circ} \mathrm{C}$ for 20 min and quickly cooled and centrifuged at $10,000 \mathrm{rpm}$ for 10 $\min$. The absorbance was measured at 450 , 532, and $600 \mathrm{~nm}$. MDA concentrations were calculated by subtracting $\mathrm{OD}_{600}$ from $\mathrm{OD}_{532}$ and $\mathrm{OD}_{450}$.

Antioxidant enzyme activity assay. Fresh leaf samples $(0.5 \mathrm{~g}$ each) were pulverized and suspended in $8 \mathrm{~mL}$ ice-cold $50 \mathrm{~mm}$ phosphate-buffered saline ( $\mathrm{pH}$ 7.8) containing $0.1 \mathrm{~mm}$ ethylenediamine tetra-acetic acid and $1 \%(\mathrm{~m} / \mathrm{v})$ polyvinylpolypyrrolidone in a chilled mortar. The homogenates were centrifuged at $12,000 g_{\mathrm{n}}$ for $20 \mathrm{~min}$ at $4{ }^{\circ} \mathrm{C}$, and the resulting supernatant was used to assay the enzyme activity.

SOD and POD activity were measured as described by Bai et al. (2010). CAT activity was evaluated by monitoring the decrease in absorbance at $240 \mathrm{~nm}$ resulting from the decomposition of $\mathrm{H}_{2} \mathrm{O}_{2}$ according to the methods of Sairam and Srivastava (2010).

Chl content determination. Chl content was measured according to Liu et al. (2012). Samples $(0.2 \mathrm{~g})$ were extracted in ethanolacetone $(1: 1, \mathrm{v} / \mathrm{v})$ at room temperature to determine the contents of $\mathrm{Chl}$ a and $\mathrm{Chl}$ b with a spectrophotometer $(752 \mathrm{~N}$ ultraviolet; Shanghai Yidian, China) at $663 \mathrm{~nm}$ and $645 \mathrm{~nm}$. Chl contents (measured in milligrams per liter) were calculated using the formula $\mathrm{Chl} \mathrm{a}=12.7 \mathrm{~A}_{663}-2.69 \mathrm{~A}_{645}$ and $\mathrm{Chl}$ $\mathrm{b}=22.9 \mathrm{~A}_{663}-4.68 \mathrm{~A}_{645}$.

Statistical analysis. Statistical analysis was conducted using SPSS version 19.0. All data were analyzed using a two-way analysis of variance, and differences between means were assessed using Duncan's multiple range 
tests $(P<0.05)$. In all figures, the spread of values is shown as error bars representing SE.

\section{Results}

Morphological features of areca seedlings. The leaves of areca seedlings are elongated and lanceolate in shape and dark green in color. There was no difference in the aerial and subterranean parts of areca seedlings between the SAP and no SAP in irrigation treatment A. However, an obvious difference was observed in the subterranean parts between areca seedlings growing under $\mathrm{M}$ and $\mathrm{D}$. We noticed that the seedlings under $M$ and $D$ showed an obvious increment in the number of fibrous roots resulting from SAP application, indicating that SAP improved the development of the roots, which was restrained in areca seedlings under drought stress (Fig. 1).

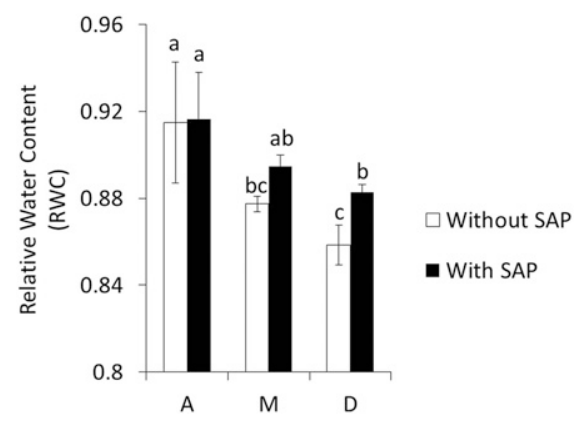

Fig. 3. Relative water content in the leaves of $A$. catechu under various irrigation (A, adequate; M, moderate; D, deficit) and superabsorbent polymer (SAP) treatments. The small bars show SD. Different letters represent significant differences at $P<0.05$ according to Duncan's multiple range tests.
SAP improved the growth of areca seedlings under drought. It was difficult to determine from morphological appearance, especially of the aerial parts, whether an areca seedling was damaged by drought. With the increasing degree of drought, the fresh weight and dry weight of both aerial and subterranean parts had significantly declined, indicating that drought stress impeded the growth of the seedlings. Compared with controls, seedlings growing with SAP showed a significant improvement of fresh weight and dry weight both in aerial or subterranean parts under $\mathrm{M}$ and $\mathrm{D}$ (Fig. 2). No variation in fresh weight and dry weight introduced by SAP application was observed in seedlings under A, suggesting that SAP cannot improve seedling growth under nondrought conditions.

RWC was measured to validate the function of SAP on water retention. RWC of areca leaves under $\mathrm{A}$ was much greater than that under $\mathrm{M}$ and $\mathrm{D}$. The RWC value decreased significantly-by $4.1 \%$ under $M$ and by $6.15 \%$ under $\mathrm{D}$ compared with $\mathrm{A}$. When SAP was applied, RWC of seedlings under $D$ increased significantly, and the RWC value was comparable to that of seedlings under $\mathrm{M}$ without SAP, demonstrating the potential impact on plant-water relations that potting media water-holding capacity can have (Fig. 3).

Cell membrane damage under drought was alleviated by SAP. Drought stress causes cell membrane damage by inducing the accumulation of ROS. We detected the activity of three ROS antioxidant enzymes in areca leaves under different conditions (Fig. 4). The results showed that SOD activity decreased by $9.3 \%$ in seedlings under $\mathrm{D}$, but no obvious changes were observed between $\mathrm{M}$ and A. POD activity also decreased by $12.1 \%$ in seedlings under $\mathrm{D}$ in the no-SAP
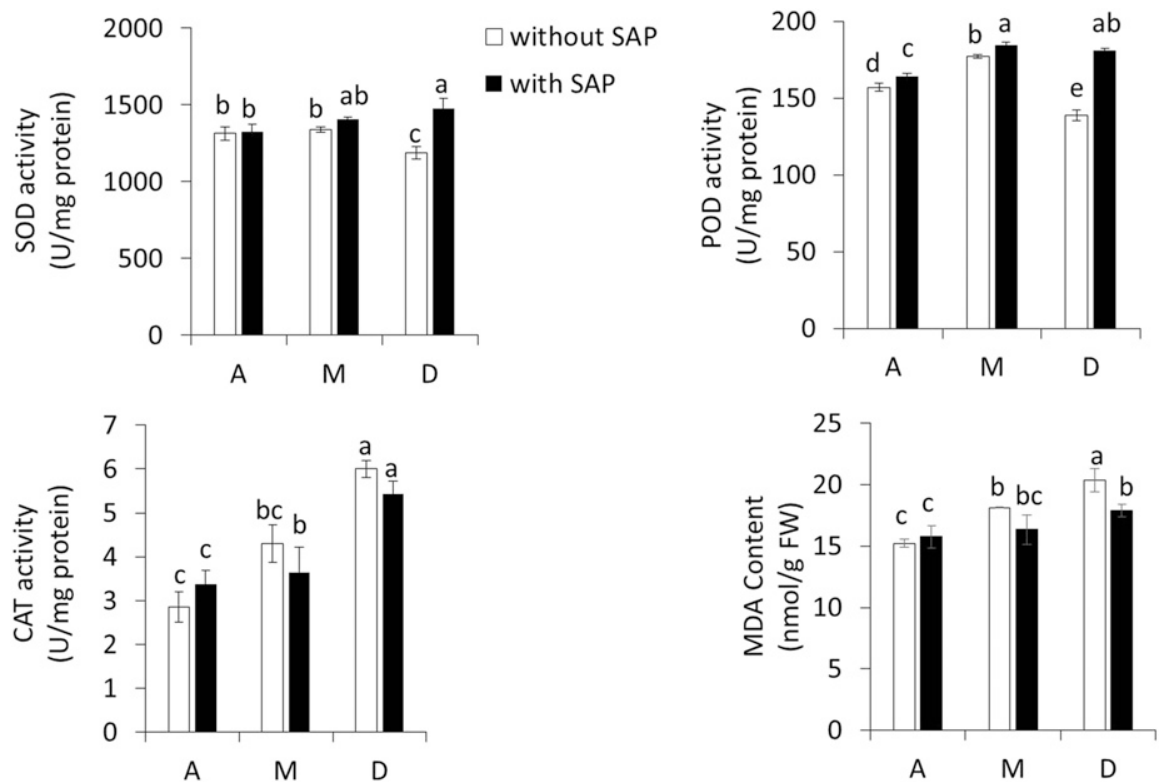

Fig. 4. The enzyme activity of superoxide dismutase (SOD), peroxidase (POD), catalase (CAT), and malondialdehyde (MDA) content in the leaves of $A$. catechu seedlings under various irrigation (A, adequate; $\mathrm{M}$, moderate; $\mathrm{D}$, deficit) and superabsorbent polymer (SAP) treatments. Different letters represent significant differences at $P<0.05$ according to Duncan's multiple range tests. treatments, but it increased by $12.7 \%$ in seedlings under M. SAP application enhanced SOD and POD activity significantly in seedlings under both $\mathrm{M}$ and $\mathrm{D}$, suggesting SAP application improved SOD and POD activity under both drought and nondrought conditions. CAT activity in the leaves was lowest under A but increased by $50.5 \%$ and $110.2 \%$ under $\mathrm{M}$ and $\mathrm{D}$ respectively. Application of SAP reduced CAT activity by $15.4 \%$ and $9.34 \%$ under $M$ and $D$ respectively. MDA content in leaves increased by $19.1 \%$ and $33.6 \%$ under $\mathrm{M}$ and $\mathrm{D}$, compared with A. Application of SAP prevented lipid peroxidation by reducing MDA content in the leaves. MDA content under A did not change with SAP application but decreased by $9.98 \%$ and $12.18 \%$ under $\mathrm{M}$ and $\mathrm{D}$, respectively. These results suggest SAP application could relieve cell membrane damage caused by drought by improving SOD and POD activity; there was little effect on CAT activity.

Effects of SAP on photosynthesis parameters. To analyze the effects of SAP on photosynthetic capacity, we first measured the chl content in areca leaves under different conditions (Fig. 5). No changes were found between the leaves growing with SAP and those growing without SAP under A. However, obvious decreases of chl a and chl $b$ were observed in the leaves growing without SAP under $M$ and $D$. With regard to carotenoids, there was no difference between SAP and no-SAP treatments under different irrigation conditions. This indicates that SAP application increased chl a and chl $b$ content of seedlings significantly under $M$ and D (Fig. 5).

We then measured the chl fluorescence parameters in areca leaves under different irrigation (Fig. 6). $\mathrm{F}_{\mathrm{v}} / \mathrm{F}_{\mathrm{m}}$ declined by $6.6 \%$ and $9.6 \%$ under $\mathrm{M}$ and $\mathrm{D}$ as compared with $\mathrm{A}$, and was increased significantly by SAP application under D. In contrast, SAP application increased the $\mathrm{Y}$ (II) and $\mathrm{qP}$ value in seedlings under drought, and it had a greater effect on seedlings under M and D. However, there was no significant improvement in seedlings under A. For NPQ, significant changes were observed only in seedlings under D.

\section{Discussion}

SAP has been established as a soil conditioner to reduce soil water loss and increase crop yield (Li et al., 2014). Maintaining a high water content in the root environment enables plants to grow better without facing stress problems. The results of the current study clearly show that SAP application had a positive effect on morphological features and biomass accumulation of areca seedlings, and it improved the survival and growth of seedlings growing under drought stress, especially under D. Similar results have been reported in other herbaceous and woody plants (Beniwal, 2011; Sivapalan 2006).

Areca seedlings under $\mathrm{M}$ showed drought resistance in the current study, and their growth can be improved efficiently by SAP 


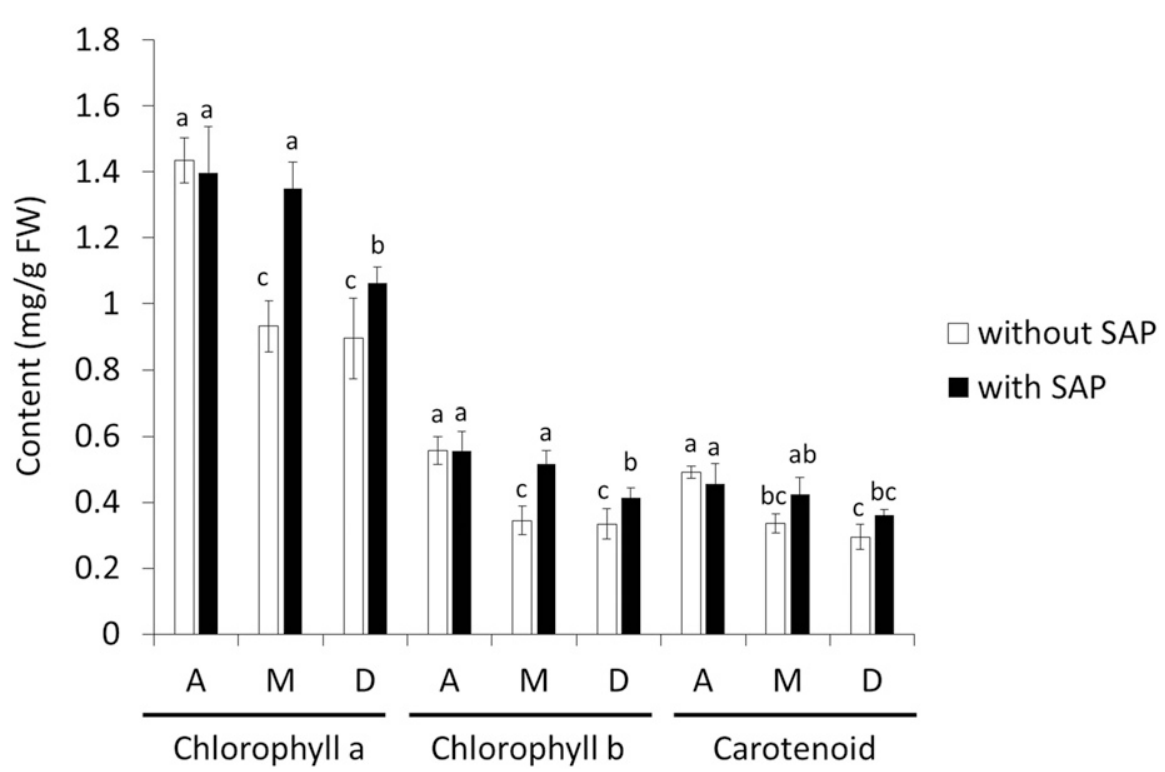

Fig. 5. The content of chlorophyll a, chlorophyll b, and carotenoids in the leaves of $A$. catechu seedlings under various irrigation (A, adequate; $\mathrm{M}$, moderate; $\mathrm{D}$, deficit) and superabsorbent polymer (SAP) treatments. Different letters in each pigment represent significant differences at $P<0.05$ according to Duncan's multiple range tests.
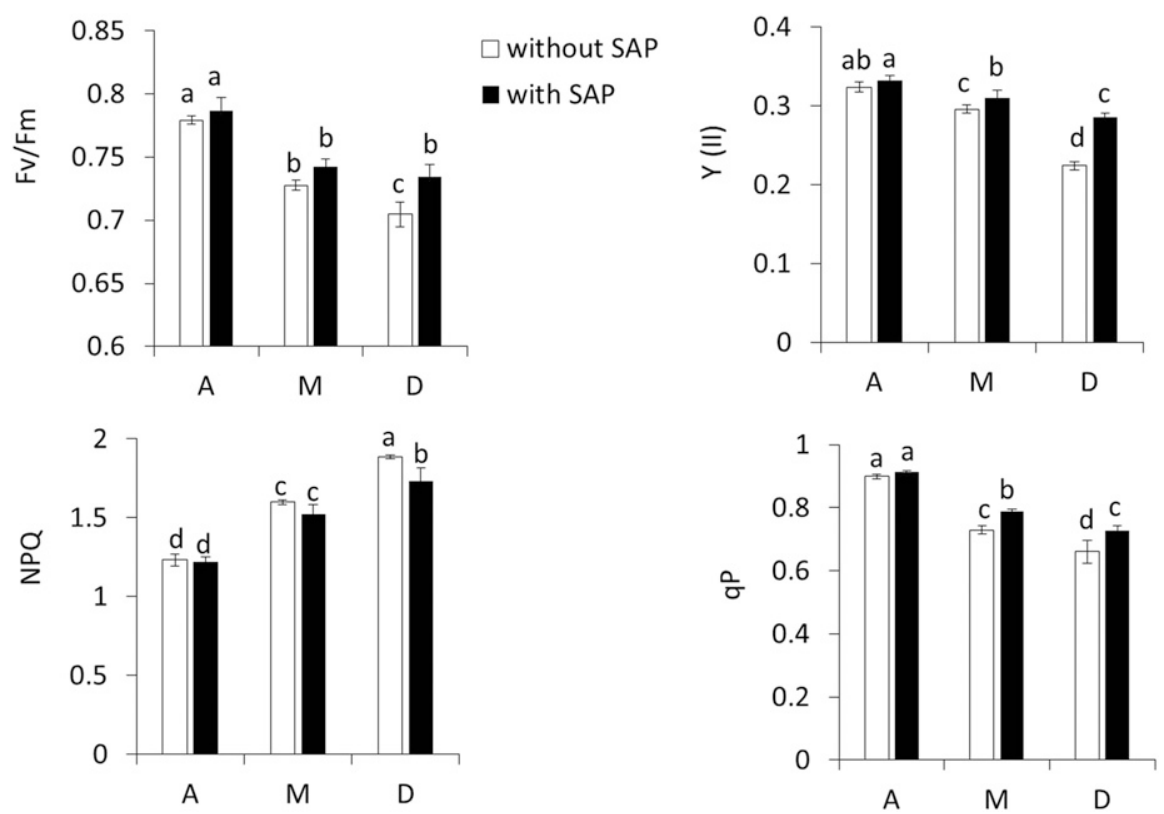

Fig. 6. Maximum photochemical efficiency of PSII $\left(\mathrm{F}_{\mathrm{v}} / \mathrm{F}_{\mathrm{m}}\right)$, actual photochemical efficiency of PSII [Y(II)], nonphotochemical quenching (NPQ), and photochemical quenching (qP) in the leaves of $A$. catechu seedlings under various irrigation (A, adequate; $\mathrm{M}$, moderate; $\mathrm{D}$, deficit) and superabsorbent polymer (SAP) treatments. Different letters represent significant differences at $P<0.05$ according to Duncan's multiple range tests.

application. On the other hand, $20 \pm 5 \%$ field water capacity (water deficit or severe drought) is negative for areca seedlings, which showed more significant physiological changes under this condition. Less than $20 \pm$ $5 \%$ field water capacity will cause significant decreases in water retention and growth of seedlings. This threshold should be a critical point for areca cultivation.

Because plant-water relations play a key role in the activation and/or modulation of antioxidant defense mechanism under drought by CAT and POD (Liu et al., 2012). With increasing drought stress, the accumulation of ROS increased, MDA accumulation in rice leaf increased, and membrane lipid peroxidation also increased (Fukao et al., 2011). This study showed that the growth of MDA content in the leaves of seedlings decreased significantly by application of SAP under D. This indicates that treatment with SAP made plants maintain a lower level of MDA content and favored the scavenging of ROS to reduce plant membrane lipid peroxidation and reduce the degree to which lipid membranes were damaged. The lesser MDA content and greater SOD and POD activity suggests reduced damage to membranes and more effective scavenging ROS in the SAP treatment lines. Greater enzyme activities under drought stress were associated with a more efficient antioxidant system response, assisting in providing tolerance against drought stress (Boaretto et al., 2014). This indicates that adding SAP can improve the defense of plant leaves against drought stress by regulating the activity of protective enzymes.

Chl content in leaves is an indicator of stress tolerance. However, greater chl content of areca seedlings under $\mathrm{M}$ and $\mathrm{D}$ by SAP application was observed. This increase in chl content improves photosynthetic efficiency and enhances plant tolerance against stress. Chl fluorescence analysis is becoming an increasingly popular technique to detect photosynthetic physiological conditions and to investigate the mechanism of photosynthesis (Liu et al., 2015). $\mathrm{F}_{\mathrm{v}} / \mathrm{F}_{\mathrm{m}}$ is a measure of the maximum photochemical efficiency of PSII when all the reaction centers are opened. When plants suffer severe drought stress, $\mathrm{F}_{\mathrm{v}} / \mathrm{F}_{\mathrm{m}}$ declines (Woo et al., 2008). Our study showed that drought stress reduced $\mathrm{F}_{\mathrm{v}} / \mathrm{F}_{\mathrm{m}}$, indicating that the original light energy conversion efficiency was reduced, and the potential of active centers was damaged, which suppressed the primary photosynthetic reaction of areca seedlings. The result was consistent with the views of Jedmowski et al. (2013). Y(II) correlates positively with PSII activities and can be used to evaluate the transfer rate of photosynthetic PSII to PSI electrons (Krall and Edwards, 1992). This study showed that Y(II) gradually decreased with increasing drought stress. Similar results have been reported in sugar beet seedlings ( $\mathrm{Li}$ et al., 2014). The result suggests that the photosynthetic apparatus PSII of areca seedlings leaves was damaged and lost its heat dissipation capability. The decrease of $\mathrm{F}_{\mathrm{v}} / \mathrm{F}_{\mathrm{m}}$, $\mathrm{Y}(\mathrm{II})$, and $\mathrm{qP}$ in areca seedlings under drought indicates the PSII system in leaves was damaged and the heat dissipation function was suppressed. However, the decrease in chl fluorescence parameters can be reduced effectively by SAP treatment, which indicates that the photon destruction mechanism of areca photosynthesis is effectively started. The efficiency in transmission of antenna pigments to the PSII reaction center was reduced and the heat dissipation capacity was increased, which reduced the accumulation of excess light in the reaction center 
and protected the photosynthetic mechanism from damage. Combined with the response of antioxidant enzymes to the change in soil water content, it was deduced that PSII light energy conversion and active oxygen metabolism play a synergistic and important role in stabilizing the function of photosynthesis. In the current study, the addition of SAP reduced the rate of decline of the soil water level, had a positive effect on leaf water potential, and alleviated the harmful effects of drought stress on the internal physiological mechanism of photosynthesis.

Application of SAP could improve the soil water-holding capacity and allow the soil to hold much more water, thereby preventing water deficiency and enhancing growth (Tohidimoghadam et al., 2009). Thus, SAP application would ensure more available water for the plants and reduce oxidative stress at phytophysiological levels, resulting in better growth and biomass production under drought stress. For areca planting, when and how SAP should be applied deserve further research.

\section{Literature Cited}

Apel, K. and H. Hirt. 2004. Reactive oxygen species: Metabolism, oxidative stress, and signal transduction. Annu. Rev. Plant Biol. 55:373399.

Aref, I.M., A.I. Ahmed, P.R. Khan, H.A. El-Atta, and M. Iqbal. 2013. Drought-induced adaptive changes in the seedling anatomy of Acacia ehrenbergiana and Acacia tortilis subsp. raddiana. Trees (Berl.) 27:959-971.

Bai, T., C. Li, F. Ma, F. Feng, and H. Shu. 2010. Responses of growth and antioxidant system to root-zone hypoxia stress in two Malus species. Plant Soil 327:95-105.

Barrs, H.D. and P.E. Weatherley. 1962. A reexamination of the relative turgidity technique for estimating water deficits in leaves. Austral. J. Biol. Sci. 15:413-428.

Beniwal, R.S. 2011. Amelioration of planting stress by soil amendment with a hydrogelmycorrhiza mixture for early establishment of beech (Fagus sylvatica L.) seedlings. Ann. For. Sci. 68:803-810.

Boaretto, L.F., G. Carvalho, L. Borgo, S. Creste, M.G. Landell, P. Mazzafera, and R.A. Azevedo. 2014. Water stress reveals differential antioxidant responses of tolerant and non-tolerant sugarcane genotypes. Plant Physiol. Biochem. 74:165-175.

Busscher, W.J., D.L. Bjorneberg, and R.E. Sojka. 2009. Field application of PAM as an amendment in deep-tilled US southeastern coastal plain soils. Soil Tillage Res. 104:215-220.

Flexas, J., M. Ribas-Carbó, A. Diaz-Espejo, J. Galmés, and H. Medrano. 2010. Mesophyll conductance to $\mathrm{CO} 2$ : Current knowledge and future prospects. Plant Cell Environ. 31:602621.

Fukao, T., E. Yeung, and J. Baileyserres. 2011. The submergence tolerance regulator SUB1A mediates crosstalk between submergence and drought tolerance in rice. Plant Cell 23:412-427.
Gill, S.S. and N. Tuteja. 2010. Reactive oxygen species and antioxidant machinery in abiotic stress tolerance in crop plants. Plant Physiol. Biochem. 48:909-930.

Guo, Y.Y., H.Y. Yu, D.S. Kong, F. Yan, and Y.J. Zhang. 2016. Effects of drought stress on growth and chlorophyll fluorescence of Lycium ruthenicum Murr. seedlings. Photosynthetica 54:524-531.

Islam, M.R., X. Xue, S. Li, C. Ren, A.E. Eneji, and Y. Hu. 2011. Effectiveness of water-saving superabsorbent polymer in soil water conservation for oat based on ecophysiological parameters. Commun. Soil Sci. Plan. 42:2322-2333.

Jedmowski, C., A. Ashoub, and W. Brüggemann. 2013. Reactions of Egyptian landraces of Hordeum vulgare and Sorghum bicolor to drought stress, evaluated by the OJIP fluorescence transient analysis. Acta Physiol. Plant. 35:345-354.

Jiang, M. and J. Zhang. 2001. Effect of abscisic acid on active oxygen species, antioxidative defence system and oxidative damage in leaves of maize seedlings. Plant Cell Physiol. 42:1265.

Krall, J.P. and G.E. Edwards. 1992. Relationship between photosystem II activity and $\mathrm{CO}_{2}$ fixation in leaves. Physiol. Plant. 86:180-187.

Lentz, R.D. and R.E. Sojka. 1994. Field results using polyacrylamide to manage furrow erosion and infiltration. Soil Sci. 158:158-274.

Li, X., Y.R. Liu, Y.M. Zheng, and J.Z. He. 2014. Characterization and soil environmental safety assessment of super absorbent polymers in agricultural application. Huan Jing Ke Xue 35:394-400.

Liu, B.H., L. Cheng, F.W. Ma, D. Liang, and Y.J. Zou. 2012. Influence of rootstock on drought response in young 'Gale Gala' apple (Malus domestica Borkh.) trees. J. Sci. Food Agr. 92:2421-2427.

Liu, M.H., L.T. Yi, S.Q. Yu, F. Yu, and X.M. Yin. 2015. Chlorophyll fluorescence characteristics and the growth response of Elaeocarpus glabripetalus to simulated acid rain. Photosynthetica 53:23-28.

Lu, H.B., Y.M. Qiao, X.C. Gong, H.Q. Li, Q. Zhang, Z.H. Zhao, and L.L. Meng. 2015. Influence of drought stress on the photosynthetic characteristics and dry matter accumulation of hybrid millet. Photosynthetica 53:306311.

Massacci, A., S.M. Nabiev, L. Pietrosanti, S.K. Nematov, T.N. Chernikova, K. Thor, and J. Leipner. 2008. Response of the photosynthetic apparatus of cotton (Gossypium hirsutum) to the onset of drought stress under field conditions studied by gas-exchange analysis and chlorophyll fluorescence imaging. Plant Physiol. Biochem. 46:189-195.

Ndamani, F. and T. Watanabe. 2015. Influences of rainfall on crop production and suggestions for adaptation. Intl. J. Agr. Sci. 5:367-374.

Peng, W., Y.J. Liu, N. Wu, T. Sun, X.Y. He, Y.X Gao, and C.J. Wu. 2015. Areca catechu L. (Arecaceae): A review of its traditional uses, botany, phytochemistry, pharmacology and toxicology. J. Ethnopharmacol. 164:340-356.

Porcel, R. and J.M. Ruizlozano. 2004. Arbuscular mycorrhizal influence on leaf water potential, solute accumulation, and oxidative stress in soybean plants subjected to drought stress. J. Expt. Bot. 55:1743-1750.

Rivera Méndez, Y.D., L. Moreno Chacón, C. Jarry Bayona, and H. Mauricio Romero. 2012. Physiological response of oil palm interspecific hybrids (Elaeis oleifera H.B.K. Cortes versus Elaeis guineensis Jacq.) to water deficit. Brazil. J. Plant Physiol. 24:273-280.

Sairam, R.K. and G.C. Srivastava. 2010. Water stress tolerance of wheat (Triticum aestivum L.): Variations in hydrogen peroxide accumulation and antioxidant activity in tolerant and susceptible genotypes. J. Agron. Crop Sci. 186:63-70.

Sairam, R.K., B. Vasanthan, and A. Arora. 2011. Calcium regulates Gladiolus flower senescence by influencing antioxidative enzymes activity. Acta Physiol. Plant. 33:1897-1904.

Schreiber, U., U. Schliwa, and W. Bilger. 1986. Continuous recording of photochemical and non-photochemical chlorophyll fluorescence quenching with a new type of modulation fluorometer. Photosynth. Res. 10:51-62.

Sivapalan, S. 2006. Benefits of treating a sandy soil with a crosslinked-type polyacrylamide. Austral. J. Expt. Agr. 46:579-584.

Smagin, A.V., N.B. Sadovnikova, and E.I. Nikolaeva. 2014. Thermodynamic analysis of the effect of strongly swelling polymer hydrogels on the physical state of soil and sediment samples. Eurasian Soil Sci. 47:78-88.

Sperdouli, I. and M. Moustakas. 2011. Spatiotemporal heterogeneity in Arabidopsis thaliana leaves under drought stress. Plant Biol. 14:118128.

Tohidimoghadam, H.R., A.H. Shiranirad, G. Nourmohammadi, D. Habibi, and M. Mashhadiakbarboojar. 2009. Effect of super absorbent application on antioxidant enzyme activities in Canola (Brassica napus L.) cultivars under water stress conditions. Amer. J. Agr. Biol. Sci. 4:215-223.

Tongo, A., A. Mahdavi, and E. Sayad. 2014. Effect of superabsorbent polymer Aquasorb on chlorophyll, antioxidant enzymes and some growth characteristics of Acacia victoria seedlings under drought stress. Ecopersia 2:571-583.

Wang, Y., Y. An, J. Yu, Z. Zhou, S. He, M. Ru, B Cui, Y. Zhang, R. Han, and Z. Liang. 2016. Different responses of photosystem II and antioxidants to drought stress in two contrasting populations of Sour jujube from the Loess Plateau, China. Ecol. Res. 31:761-775.

Woo, N.S., M.R. Badger, and B.J. Pogson. 2008. A rapid, non-invasive procedure for quantitative assessment of drought survival using chlorophyll fluorescence. Plant Methods 4:27.

Yaish, M.W. and P.P. Kumar. 2015. Salt tolerance research in date palm tree (Phoenix dactylifera L.), past, present, and future perspectives. Front. Plant Sci. 6:348.

Yang, P.M., Q.C. Huang, G.Y. Qin, S.P. Zhao, and J.G. Zhou. 2014. Different drought-stress responses in photosynthesis and reactive oxygen metabolism between autotetraploid and diploid rice. Photosynthetica 52:193-202.

Zohuriaan-Mehr, M.J. and K. Kabiri. 2008. Superabsorbent polymer materials: A review: Iran. Iran. Polym. J. 17:451-477. 